\title{
Cardioprotective properties of leptin in patients with excessive body mass
}

\author{
Aleksandra Paduszyńska $^{1}$ - Agata Sakowicz ${ }^{2}$ - Maciej Banach ${ }^{1,3} \cdot$ Marek Maciejewski $^{3}$ Marek Dąbrowa $^{4}$. \\ Agata Bielecka-Dąbrowa ${ }^{1,3}$
}

Received: 11 January 2020 / Accepted: 11 March 2020 / Published online: 20 March 2020

(C) The Author(s) 2020

\begin{abstract}
Background Adipose tissue is producing adipokines that play different roles in the pathophysiology of cardiovascular disease. Aims The study aimed to assess the role of selected biomarkers in hypertensive patients with overweight and obesity compared with those with normal body-mass index (BMI).

Methods A total of 62 patients with BMI $<25 \mathrm{~kg} / \mathrm{m}^{2}$ (median age $54(46-58)$ yrs., $57 \%$ males) and 51 with BMI $\geq 25 \mathrm{~kg} / \mathrm{m}^{2}$ (median age 53 (48-59) yrs., 37\% males) were enrolled. Biochemical parameters, leptin, adiponectin, and resistin; asymmetric dimethylarginine; interleukin 6; and N-terminal propeptide of type III procollagen, were assessed in plasma. The evaluation of hemodynamic parameters was performed using SphygmoCor 9.0 tonometer. Echocardiography was performed using AlokaAlpha 10 Premier device.

Results Overweight and obese patients had significantly higher concentration of leptin ( $34 \mathrm{vs} 18 \mathrm{ng} / \mathrm{ml} ; p=0.03)$, ADMA (0.43 vs $0.38 \mu \mathrm{mol} / 1, p=0.04)$, and lower concentration of adiponectin $(5.3 \mathrm{vs} 7 \mu \mathrm{g} / \mathrm{ml}, p=0.01)$. The only significant difference in tonometry analysis was higher aortic pulse pressure $(\mathrm{mmHg})$ in patients with BMI $\geq 25 \mathrm{~kg} / \mathrm{m}^{2}$ group (34 vs $\left.30 ; p=0.03\right)$. These patients had also significantly lower peak systolic velocity and early diastolic velocity in tissue Doppler imaging of the right ventricle free wall at the level of the tricuspid annulus compared with controls $(p=0.02$ and $p=0.001$, respectively). The level of leptin is correlated negatively with the left ventricular mass index (LVMI) $(R$ Spearman $=-0.5 ; p=0.002)$ and PWV $(R=-0.4$; $p=0.01)$ and ADMA with total and LDL cholesterol $(R=-0.42 ; p=0.008)$, and adiponectin is correlated positively with HDL cholesterol $(R=0.67 ; p=0.0001)$.
\end{abstract}

Conclusions Leptin concentrations were inversely proportional to LVMI and PWV in patients with BMI $<25 \mathrm{~kg} / \mathrm{m}^{2}$.

Trial registration Clinicaltrials.gov study ID: NCT04175080.

Keywords Adipokines · Hypertrophy $\cdot$ Left ventricular remodeling · Leptin

Agata Bielecka-Dąbrowa

agatbiel7@ poczta.onet.pl

1 Department of Hypertension, Chair of Nephrology and Hypertension, Medical University of Lodz, Lodz, Poland

2 Department of Medical Biotechnology, Medical University of Lodz, Lodz, Poland

3 Department of Cardiology and Congenital Diseases of Adults, Polish Mother's Memorial Hospital Research Institute (PMMHRI), Lodz, Poland

4 Department of Biopharmacy, Chair of Biopharmacy, Medical University of Lodz, Lodz, Poland

\section{Introduction}

Excessive body mass is the increasing health problem all over the world. The analysis of data collected between 1990 and 2015 revealed that cardiovascular disease was the major cause of deaths related to high body-mass index (BMI) [1]. It is the result of different changes caused by the excessive fat accumulation. Besides being an energy storage, the adipose tissue is also an endocrine organ producing adipokines like leptin, resistin, adiponectin, and interleukin 6 (IL-6) [2]. Among them particular attention is paid to leptin. This study aimed to assess the clinical role of selected biomarkers in patients with overweight and obesity compared with those with normal body-mass index (BMI). 


\section{Material and methods}

A total of 113 hypertensive pharmacologically treated patients were enrolled to this one center study. Based on the BMI, they were divided into two groups: with $\mathrm{BMI}<25 \mathrm{~kg} / \mathrm{m}^{2}$ and with BMI $\geq 25 \mathrm{~kg} / \mathrm{m}^{2}$. Basic characteristic of studied groups of patients is presented in Table 1 .

Data regarding pharmacotherapy used in the patients groups are summarized in Table 2.

In all patients, the following biochemical parameters were measured:

- Selected adipokines: Leptin, adiponectin, resistin, and IL6

- An endogenous inhibitor of nitric oxide synthase: Asymmetric dimethylarginine (ADMA)

- Biomarker of cardiac extra-cellular matrix turnover: Nterminal propeptide of type III procollagen(PIIINP)

- Lipids

- Glucose

They underwent also non-invasive assessment of hemodynamic parameters as well as echocardiography.

\section{Biochemical parameters}

Blood samples for laboratory tests were collected from patients assigned to either group in a hospital setting, thus minimizing the risk of infection in both the subject and the person collecting the sample. Laboratory tests were performed in fasting subjects in laboratory of WAM Hospital, following a minimum 12-h period after the last meal. At the initial time point of the study, $19.5 \mathrm{~mL}$ of blood were collected with a vacuum blood collection system from the basilic vein for routine laboratory tests. The serum samples were centrifuged and pipetted into Eppendorf tubes and subsequently placed in a freezer (first at $-25^{\circ} \mathrm{C}$ and then at $-70^{\circ} \mathrm{C}$ ). After the desired number of samples were obtained and their prior thawing (immediately before testing), the biochemical parameters were assessed.
Table 2 Pharmacotherapy in the studied groups of patients

\begin{tabular}{llll}
\hline Drug class & $\begin{array}{l}\text { Patients with } \\
\text { BMI }<25 \mathrm{~kg} / \\
\mathrm{m}^{2}\end{array}$ & $\begin{array}{l}\text { Patients with } \\
\text { BMI } \geq 25 \mathrm{~kg} /\end{array}$ & $p$ \\
$\mathrm{~m}^{2}$
\end{tabular}

$A C E$, angiotensin-converting enzyme; $A R B$, angiotensin receptor blocker; $A S A$, acetylsalicylic acid

\section{Adipokines, ADMA, and PIIINP}

The Enzyme Linked-Immunosorbent Assay (ELISA) tests were conducted for quantitative determination of resistin (BioVendor, Czech Republic), adiponectin (BioVendor, Czech Republic), leptin (BioVendor, Czech Republic), IL-6 (Gen-Probe, France), ADMA (Immunodiagnostic, Bensheim, Germany), and PIIINP (Cloud-Clone Corp, China) in human serum.

\section{Lipids}

Triglycerides, total, and HDL-C levels were evaluated using the AU680 device (Beckman Coulter Poland, Warsaw, Poland). The TC was measured enzymatically with standardized calibrators: cholesterol esterase and oxidase, respectively, according to the manufacturer's specifications. The HDL-C was measured enzymatically with lipoproteins immune complex with standardized calibrators: cholesterol esterase and oxidase. LDL-C concentrations were calculated by Friedewald's formula: LDL-C $(\mathrm{mmol} / \mathrm{L})=\mathrm{TC}-\mathrm{HDL}-\mathrm{C}-$ TG/2.2. TG was measured enzymatically with glycerol phosphate oxidase and $\mathrm{H} 202$ determination in the presence of peroxidase.
Table 1 Basic characteristics of studied groups of patients

\begin{tabular}{lllr}
\hline Parameter & Patients with BMI $<25 \mathrm{~kg} / \mathrm{m}^{2}$ & Patients with BMI $\geq 25 \mathrm{~kg} / \mathrm{m}^{2}$ & $p$ \\
\hline Number of patients & 62 & 51 & \\
Median age (years) & $54(46-58)$ & $53(48-59)$ & 0.46 \\
Gender (male) & $57 \%$ & $38 \%$ & 0.051 \\
BMI $\left(\mathrm{kg} / \mathrm{m}^{2}\right)$ & $22.8(20.8-24.5)$ & $28.7(27.2-32.9)$ & $<0.001$ \\
BSA $\left(\mathrm{m}^{2}\right)$ & $1.76(1.65-1.95)$ & $1.98(1.87-2.12)$ & $<0.001$ \\
Carbohydrate disturbances & $53 \%$ & $67 \%$ & 0.147 \\
\hline
\end{tabular}

$B M I$, body-mass index; $B S A$, body surface area 


\section{Glucose}

Plasma glucose was measured by ultraviolet photometry using the enzymatic reactions catalyzed by hexokinase, using Olympus reagent kits (Cat. No. OSR61221, OSR6221).

\section{Hemodynamic parameters}

Non-invasive evaluation was performed using SphygmoCor 9.0 tonometer (AtCor Medical, Sydney, Australia). The aortic systolic pressure (SP aortic), aortic diastolic pressure (DP aortic), and aortic pulse pressure (PP aortic) were obtained. We assessed also the parameters of arterial stiffness: augmentation pressure (AP), augmentation index (AIx), and pulse wave velocity (PWV). AP was calculated as the difference between the first and second systolic peaks on the central pressure waveform, which was derived by radial applanation tonometry and application of a generalized transfer function to the radial pressure waveform. AIx was calculated by AP as a percentage of the total pressure waveform height. PWV was assessed using electrocardiogram-gated sequential tonometry at the carotid and femoral sites and calculated as the path length divided by transit time (meter/s). Path length is a result of the subtraction of the distance between sternal notch and carotid recording site from the distance between sternal notch and femoral site.

\section{Echocardiography}

Echocardiography was performed using Alpha 10 Premier device (ALOKA, Tokyo, Japan) with a 3-11 MHz probe. Quantitative assessment was used according to current guidelines. The ratio of peak velocity of early diastolic transmitral flow to peak velocity of early diastolic mitral annular motion as determined by pulsed-wave Doppler $\left(\mathrm{E} / \mathrm{E}^{\prime}\right)$ was calculated as an index of the left ventricular filling pressure. The left ventricular ejection fraction (LVEF) was determined by biplane Simpson's method. The left atrial volume index (LAVI) was calculated by dividing left atrial volume by body surface area. The peak systolic velocity (Sm) and early diastolic velocity $\left(\mathrm{e}^{\prime}\right)$ were assessed using tissue Doppler.

\section{Statistical analysis}

The STATISTICA 10 software package (StatSoft, Poland), SPSS 21, R-project 3.0.1 (packages: rmsipredictAbel), was used for analysis. Results were considered significant if $p<0.05$. The Shapiro-Wilk test was used to assess the normality of distribution. To compare two groups, Student's $t$ test for continuous variables with normal distribution and MannWhitney $U$ test for non-normally distributed variables were used. For quantitative variables (continuous and discrete) to evaluate correlations between variables, Spearman's rank correlation coefficient was used.

\section{Results}

\section{Biochemical parameters}

In comparison with patients with proper body weight, those with $\mathrm{BMI} \geq 25$ had significantly higher concentrations of total leptin, ADMA, and glucose. There were no statistically significant differences in resistin, IL-6, PIIINP, and total cholesterol concentrations between groups. Overweight and obese patients had significantly lower concentrations of adiponectin, LDL, and HDL cholesterol. The results of measurements are presented in Table 3.

\section{Hemodynamic parameters}

The only significant difference $(p=0.03)$ in tonometry analysis was lower APP in BMI $\geq 25$ group in comparison with the control group. The differences between groups in aortic pressures and the parameters of arterial stiffness, AP, AIx, AIx@HR75, and PWV, were insignificant. The values of assessed parameters are compared in Table 4.

\section{Echocardiography}

As shown in Table 3, overweight and obese patients had significantly lower peak systolic velocity $(p=0,026)$ and early diastolic velocity $(p=0,002 / p=0,003$, depending on the used statistical model) in tissue Doppler imaging of RV free wall at the level of the tricuspid annulus compared with the controls. There were no differences in E/E', LAVI, LVEF, and LVMI between groups. The results of evaluated parameters are presented in Table 4.

\section{Correlations}

We determined the correlation between leptin, adiponectin, and ADMA with selected parameters in patients with $\mathrm{BMI} \geq 25$. According to results shown in Table 5, we found negative correlations of leptin with LVMI and PWV, as well as ADMA with total cholesterol and positive correlation of adiponectin with HDL cholesterol. The Roc chart for leptin is presented on Fig. 1.

\section{Discussion}

Our study focuses on the clinical role of selected biomarkers in hypertensive patients with overweight and obesity compared with those with normal BMI. In both groups, the 
Table 3 Evaluation of biochemical parameters among the groups

\begin{tabular}{llll}
\hline Parameter & $\begin{array}{l}\text { Patients with } \\
\text { BMI }<25 \mathrm{~kg} / \mathrm{m}^{2}\end{array}$ & $\begin{array}{l}\text { Patients with } \\
\text { BMI } \geq 25 \mathrm{~kg} / \mathrm{m}^{2}\end{array}$ & $p$ \\
\hline Adipokines: & & & \\
$\quad$ - Leptin $(\mathrm{ng} / \mathrm{ml})$ & $18.66(5.95-51.75)$ & $34.53(16.93-70.49)$ & $\mathbf{0 . 0 3}$ \\
- Adiponectin $(\mu \mathrm{g} / \mathrm{ml})$ & $7.07(5.03-11.12)$ & $5.36(3.90-8.62)$ & $\mathbf{0 . 0 2}$ \\
- Resistin $(\mathrm{ng} / \mathrm{ml})$ & $4.53(3.04-6.25)$ & $3.95(3.14-6.92)$ & 0.96 \\
ADMA $(\mu \mathrm{mol} / \mathrm{l})$ & $0.38(0.34-0.46)$ & $0.43(0.37-0.53)$ & $\mathbf{0 . 0 4}$ \\
IL-6 $(\mathrm{pg} / \mathrm{ml})$ & $2.53(0.76-6.01)$ & $1.42(0.56-3.38)$ & 0.06 \\
PIIINP $(\mathrm{ng} / \mathrm{ml})$ & $15.21(13.45-17.73)$ & $15.59(13.54-21.07)$ & 0.62 \\
Glucose $(\mathrm{mmol} / \mathrm{L})$ & $5.57(5.10-6.20)$ & $6.00(5.41-6.70)$ & $\mathbf{0 . 0 1}$ \\
LDL cholesterol $(\mathrm{mmol} / \mathrm{l})$ & $3.01(2.64-3.67)$ & $2.80(1.95-3.83)$ & $\mathbf{0 . 0 2}$ \\
HDL cholesterol $(\mathrm{mmol} / \mathrm{l})$ & $1.33(1.13-1.60)$ & $1.19(0.94-1.44)$ & $\mathbf{0 . 0 1}$ \\
Total cholesterol $(\mathrm{mmol} / \mathrm{l})$ & $4.98 \pm 1.34$ & $4.48 \pm 1.22$ & 0.17 \\
\hline
\end{tabular}

For the parameters with non-normal distribution, there are given median values (lower and higher values). For the parameter with normal distribution there are given mean values \pm standard deviation (SD). ADMA, asymmetric dimethylarginine; $I L-6$, interleukin 6; PIIINP, N-terminal propeptide of type III procollagen; $L D L$, low density lipoprotein; $H D L$, high density lipoprotein concentration of PIIINP suggests the risk of heart failure [3, 4]. We found a positive correlation between adiponectin and HDL and a negative correlation between ADMA and LDL and total cholesterol. We also observed potential influence of leptin on cardiac remodeling in hypertensive patients.

The observed significant difference in adiponectin concentrations between the studied groups corresponds to the lower concentrations of HDL in the obese and overweight patients. Our findings are consistent with the published data obtained from the studies on larger population. Similar results were also noted in the study in patients with type 2 diabetes [5]. However the analysis performed by Borges MC et al. [6] indicates the limited clinical benefits of this correlation. The lack of potential therapeutic use resulted from the unestablished direct effect of adiponectin on lipid profile. Probably adiponectin concentrations are reflecting other factors causing the changes in lipid profile or are dependent on a disease.

The groups in our study differ also significantly in ADMA concentrations, and in obese and overweight patients, we found a negative correlation between ADMA and LDL and
Table 4 Evaluation of hemodynamic and echocardiographic parameters among the groups

\begin{tabular}{llll}
\hline Parameter & Patients with BMI $<25 \mathrm{~kg} / \mathrm{m}^{2}$ & Patients with BMI $\geq 25 \mathrm{~kg} / \mathrm{m}^{2}$ & $p$ \\
\hline DP aortic $(\mathrm{mmHg})$ & $81(75-88)$ & $85(78-92)$ & 0.37 \\
SP aortic $(\mathrm{mmHg})$ & $119.94 \pm 18.68$ & $124.47 \pm 17.41$ & 0.37 \\
AP $(\mathrm{mmHg})$ & $8(5-17)$ & $11(7-16)$ & 0.97 \\
AIx $(\%)$ & $24.67 \pm 13.63$ & $23.65 \pm 11.07$ & 0.78 \\
AIx $@$ HR75 & $21.48 \pm 11.95$ & $20.88 \pm 11.09$ & 0.85 \\
PWV & $6.9(6.0-8.4)$ & $7.6(6.3-8.9)$ & 0.29 \\
APP $(\mathrm{mmHg})$ & $34.0(29.5-38.5)$ & $30.0(23.0-38.0)$ & $\mathbf{0 . 0 3}$ \\
E/E' & $6.68(5.53-8.00)$ & $7.30(6.00-8.84)$ & 0.18 \\
LAVI $\left(\mathrm{ml} / \mathrm{m}^{2}\right)$ & $24.92 \pm 10.52$ & $23.25 \pm 8.04$ & 0.57 \\
LVEF $(\%)$ & $60.0(57.5-65.0)$ & $60.0(55.0-64.0)$ & 0.23 \\
LVMI $\left(\mathrm{g} / \mathrm{m}^{2}\right)$ & $101(83-119)$ & $104(87-117)$ & 0.88 \\
Sm $(\mathrm{cm} / \mathrm{s})$ & $13.80(12.00-16.70)$ & $12.65(11.00-15.00)$ & $\mathbf{0 . 0 2}$ \\
$\mathrm{e}^{\prime}(\mathrm{cm} / \mathrm{s})$ & $14.66 \pm 4.38$ & $12.13 \pm 2.15$ & $\mathbf{0 . 0 0 3}$ \\
\hline
\end{tabular}

For the parameters with non-normal distribution, there are given median values (lower and higher values). For the parameters with normal distribution, there are given mean values \pm standard deviation (SD). $D P$, aortic, diastolic pressure aortic; $S P$, aortic, systolic pressure aortic; $A P$, augmentation pressure; $A I x$, augmentation index; $A I x @ H R 75$, adjusted augmentation index at heart rate 75 per minute; $P W V$, pulse wave velocity; $A P P$, aortic pulse pressure; $E / E^{\prime}$, ratio of peak velocity of early diastolic transmitral flow to peak velocity of early diastolic mitral annular motion as determined by pulsed wave Doppler; $L A V I$, left atrial volume index; $L V E F$, left ventricular ejection fraction; $L V M I$, left ventricular mass index; $S m$, peak systolic velocity; $e^{\prime}$, early diastolic velocity 
Table 5 Spearman's rank correlation of leptin, adiponectin and ADMA with selected parameters in patients with $\mathrm{BMI} \geq 25$

\begin{tabular}{llll}
\hline & Leptin & Adiponectin & ADMA \\
\hline LDL cholesterol & $\mathrm{ns}$ & $\mathrm{ns}$ & $-0.38(p=0.02)$ \\
HDL cholesterol & $\mathrm{ns}$ & $0.67(p=0.0001)$ & $\mathrm{ns}$ \\
Total cholesterol & $\mathrm{ns}$ & $\mathrm{ns}$ & $-0.42(p=0.008)$ \\
PWV & -0.4 & $\mathrm{~ns}$ & $\mathrm{~ns}$ \\
& $(p=0.01)$ & & $\mathrm{ns}$ \\
LVMI & -0.5 & $\mathrm{~ns}$ & \\
& $(p=0.002)$ & & \\
\hline
\end{tabular}

$L D L$, low density lipoprotein; $H D L$, high density lipoprotein; $P W V$, pulse wave velocity; $L V M I$, left ventricular mass index; ns, not significant

total cholesterol. Surprisingly the concentrations of LDL and total cholesterol were lower in the patients whose BMI exceeds $25 \mathrm{~kg} / \mathrm{m}^{2}$ (possible reason is the effect of statins used more frequently in this group). These results are in contrary to the established role of ADMA as a cardiovascular risk marker $[7,8]$. The study on larger population including patients before and during dyslipidemia therapy is needed to formulate unequivocal conclusion.

Obtained results indicate protective role of leptin in LV remodeling.

Leptin has complex and pleiotropic effects, which are not fully explained $[9,10]$. The recent reviews aim to summarize current knowledge and present network of signaling pathways as well as interactions with cardiovascular system [11-13]. Translation of the research results into the clinical practice is an opportunity for better prevention and treatment. However, it has not been resolved which of the leptin effects outweigh,

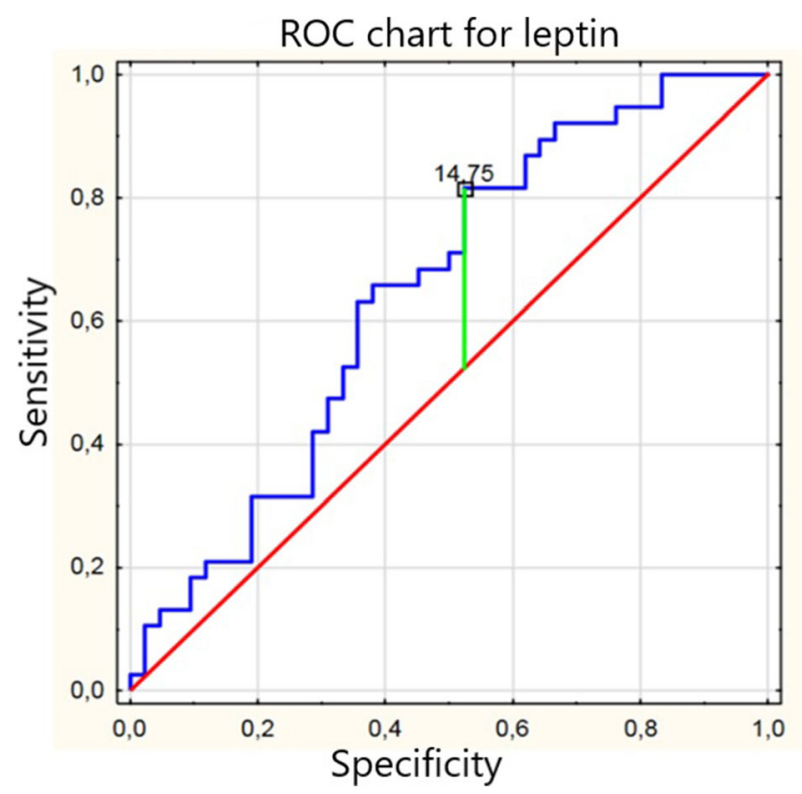

Fig. 1 ROC chart for leptin adverse whether cardioprotective. Available non-clinical data are conflicting. They indicate either the role of leptin in the cardiomyocytes hypertrophy $[14,15]$ or its antihypertrophic effect $[16,17]$. These differences are probably related to studies' design. Also the results of clinical observations are equivocal and depend on many factors, for example, the characteristic of studied groups. The elevated concentration of leptin is confirmed in patients with heart failure, both with reduced and preserved ejection fraction [18]. Hyperleptinemia occurs also in majority of overweight and obese patients, but it is accompanied by resistance to leptin action [19].

Our observations are in line with large epidemiological study in which high levels of leptin were not associated with higher incidence of cardiovascular disease [20], whereas some studies on smaller groups indicate pro-hypertrophic effect of leptin [21-23]. Although it was found that hypertrophic effect of leptin is independent from the blood pressure values [21, 22], high blood pressure has the important role in developing LV hypertrophy [24]. In our study, diastolic and systolic pressure values do not differ significantly among the groups, and either patients with $\mathrm{BMI}<25 \mathrm{~kg} / \mathrm{m}^{2}$ or patients with $\mathrm{BMI} \geq$ $25 \mathrm{~kg} / \mathrm{m}^{2}$ had properly pharmacologically controlled hypertension. It is suggested that in the overweight and obese patients, the influence of leptin on the satiety is blocked, whereas resistance on other effects does not occur. Study of larger group is needed to assess whether the normal blood pressure in overweight and obese patients is an effect of therapy or a resistance to leptin pressor action. Data reviewed by Mark AL [25] indicate variation in leptin gene and receptor as possible causes of differences in blood pressure response. Moreover the administration of leptin does not result in the increase of blood pressure.

Another factor that can contribute to the obtained results is the localization of leptin synthesis. Plasma concentration of leptin corresponds mainly to its synthesis by adipocytes. Recent study on murine model suggests that the hypertrophic action is related to the overexpression of cardiac leptin [26]. The limitations of available measurement methods make it impossible to determine the concentration of cardiac leptin in samples from patients. However, it cannot be excluded that the observed lack of LV remodeling is the effect of low cardiac leptin synthesis in the studied obese and overweight patients. The relationship between leptin, abdominal adiposity, and arterial stiffness was assessed on large group of patients by Windham et al. [27]. The results suggest that increased pulse wave velocity associated with leptin do not depend on abdominal obesity. Beside the production by body adipose tissue, the increased concentrations of leptin may be also a result of other factors, for example, genetic.

The limitations of our study such as small sample size, characteristic of studied groups (including sex differences), and study methods should be taken into consideration while formulating the conclusions. However, the protective role of 
leptin in overweight and obese patients was also found in the study of Kamimura et al. [28]. The significant effect on LV hypertrophy and stiffness was reported in black obese women. Left ventricular mass was lower $(p=0,008$ in model adjusted for age and BMI and $p=0,004$ in model adjusted for age, BMI, diabetes, coronary heart disease, systolic blood pressure, antihypertensive medication, glomerular filtration rate, and smoking status) and diastolic wall strain was higher ( $p=$ 0,004 and 0,007 , respectively). The same influence of leptin was observed in men but was not statistically significant [28]. The results of the study of Lieb et al. [29] also support our observations. Echocardiographic characteristic and leptin concentration of 432 older patients ( $>70$ years of age) with the mean BMI $>25 \mathrm{~kg} / \mathrm{m}^{2}$ were evaluated. The higher concentration of leptin was associated with lower left ventricular mass and wall thickness as well as left atrial size [29].

\section{Conclusions}

Higher leptin concentrations were inversely proportional to left ventricular mass index and pulse wave velocity in patients with overweight and obesity. Further studies are necessary to confirm these results and to establish the potential cardioprotective factors in patients whose $\mathrm{BMI} \geq 25 \mathrm{~kg} / \mathrm{m}^{2}$.

\section{Compliance with ethical standards}

Conflict of interest The authors declare that they have no conflict of interest.

Ethical approval All procedures performed in studies involving human participants were in accordance with the ethical standards of the institutional and/or national research committee and with the 1964 Helsinki Declaration and its later amendments. The study protocol was approved by Bioethics Committee of Medical University of Lodz (RNN/80/17/KE).

Comparable ethical standards This article does not contain any studies with animals performed by any of the authors.

Informed consent Informed consent was obtained from all individual participants included in the study. All patients gave informed consent prior to the procedure.

Open Access This article is licensed under a Creative Commons Attribution 4.0 International License, which permits use, sharing, adaptation, distribution and reproduction in any medium or format, as long as you give appropriate credit to the original author(s) and the source, provide a link to the Creative Commons licence, and indicate if changes were made. The images or other third party material in this article are included in the article's Creative Commons licence, unless indicated otherwise in a credit line to the material. If material is not included in the article's Creative Commons licence and your intended use is not permitted by statutory regulation or exceeds the permitted use, you will need to obtain permission directly from the copyright holder. To view a copy of this licence, visit http://creativecommons.org/licenses/by/4.0/.

\section{References}

1. GBD 2015 Obesity Collaborators (2017) Health effects of overweight and obesity in 195 countries over 25 years. N Engl J Med 377(1):13-27. https://doi.org/10.1056/NEJMoa1614362

2. Jung UJ, Choi MS (2014) Obesity and its metabolic complications: the role of adipokines and the relationship between obesity, inflammation, insulin resistance, dyslipidemia and nonalcoholic fatty liver disease. Int J Mol Sci 15(4):6184-6223. https://doi.org/10.3390/ ijms15046184

3. Bielecka-Dąbrowa A, Michalska-Kasiczak M, Gluba A et al (2015) Biomarkers and echocardiographic predictors of myocardial dysfunction in patients with hypertension. Sci Rep 5:8916. https://doi. org/10.1038/srep08916

4. Bielecka-Dąbrowa A, Gluba-Brzózka A, Michalska-Kasiczak M et al (2015) The multi-biomarker approach for heart failure in patients with hypertension. Int J Mol Sci 16(5):10715-10733. https:// doi.org/10.3390/ijms160510715

5. Kapłon-Cieślicka A, Postuła M, Rosiak M et al (2015) Association of adipokines and inflammatory markers with lipid control in type 2 diabetes. Pol Arch Med Wewn 125(6):414-423. https://doi.org/10. 20452/pamw. 2880

6. Borges MC, Barros AJD, Ferreira DLS, Casas JP, Horta BL, Kivimaki M, Kumari M, Menon U, Gaunt TR, Ben-Shlomo Y, Freitas DF, Oliveira IO, Gentry-Maharaj A, Fourkala E, Lawlor DA, Hingorani AD (2017) Metabolic profiling of adiponectin levels in adults: Mendelian randomization analysis. Circ Cardiovasc Genet 10(6):e001837. https://doi.org/10.1161/ CIRCGENETICS.117.001837

7. Nishiyama Y, Ueda M, Katsura K et al (2010) Asymmetric dimethylarginine (adma) as a possible risk marker for ischemic stroke. J Neurol Sci 290(1-2):12-15. https://doi.org/10.1016/j.jns. 2009.12.020.epub2010jan8

8. Fliser D (2005) Asymmetric dimethylarginine (adma): the silent transition from an 'uraemic toxin' to a global cardiovascular risk molecule. Eur J Clin Investig 35(2):71-79

9. Stępień M, Stępień A, Banach M et al (2014) New obesity indices and adipokines in normotensive patients and patients with hypertension: comparative pilot analysis. Angiology 65(4):333-342. https://doi.org/10.1177/0003319713485807

10. Stępień M, Stępień A, Wlazeł RN, Paradowski M, Banach M, Rysz M, Rysz J (2013) Obesity indices and adipokines in non-diabetic obese patients with early stages of chronic kidney disease. Med Sci Monit 19:1063-1072

11. Mechanick JI, Zhao S, Garvey WT (2016) The adipokinecardiovascular-lifestyle network: translation to clinical practice. J Am Coll Cardiol 68(16):1785-1803. https://doi.org/10.1016/j.jacc. 2016.06.072

12. Mechanick JI, Zhao S, Garvey WT (2018) Leptin, an adipokine with central importance in the global obesity problem. Glob Heart 13(2):113-127. https://doi.org/10.1016/j.gheart.2017.10.003

13. Katsiki N, Mikhailidis DP, Banach M (2018) Leptin, cardiovascular disease and type 2 diabetes mellitus. Acta Pharmacol Sin 39(7): 1176-1188. https://doi.org/10.1038/aps.2018.40

14. Rajapurohitam V, Gan XT, Kirshenbaum LA, Karmazyn M (2003) The obesity-associated peptide leptin induces hypertrophy in neonatal rat ventricular myocytes. Circ Res 93(4):277-279. https://doi. org/10.1161/01.RES.0000089255.37804.72

15. Tajmir P, Ceddia RB, Li RK, Coe IR, Sweeney G (2004) Leptin increases cardiomyocyte hyperplasia via extracellular signalregulated kinase- and phosphatidylinositol 3-kinase-dependent signaling pathways. Endocrinology 145(4):1550-1555. https://doi. org/10.1210/en.2003-1128

16. Barouch LA, Berkowitz DE, Harrison RW, O'Donnell CP, Hare JM (2003) Disruption of leptin signaling contributes to cardiac 
hypertrophy independently of body weight in mice. Circulation 108(6):754-759. https://doi.org/10.1161/01.CIR.0000083716. 82622.FD

17. McGaffin KR, Sun CK, Rager JJ, Romano LC, Zou B, Mathier MA, O'Doherty RM, McTiernan C, O'Donnell CP (2008) Leptin signalling reduces the severity of cardiac dysfunction and remodeling after chronic ischaemic injury. Cardiovase Res 77(1):54-63. https://doi.org/10.1093/cvr/cvm023

18. Faxén UL, Hage C, Andreasson A, Donal E, Daubert JC, Linde C, Brismar K, Lund LH (2017) HFpEF and HFrEF exhibit different phenotypes as assessed by leptin and adiponectin. Int J Cardiol 228: 709-716. https://doi.org/10.1016/j.ijcard.2016.11.194

19. Sahu A (2004) Minireview: a hypothalamic role in energy balance with special emphasis on leptin. Endocrinology 145(6):2613-2620. https://doi.org/10.1210/en.2004-0032

20. Martin SS, Blaha MJ, Muse ED, Qasim AN, Reilly MP, Blumenthal RS, Nasir K, Criqui MH, McClelland R, HughesAustin JM, Allison MA (2015) Leptin and incident cardiovascular disease: the multi-ethnic study of atherosclerosis (MESA). Atherosclerosis 239(1):67-72. https://doi.org/10.1016/j. atherosclerosis.2014.12.033

21. Paolisso G, Taglaimonte MR, Galderisi M et al (2001) Plasma leptin concentration, insulin sensitivity, and 24-hour ambulatory blood pressure and left ventricular geometry. Am J Hypertens 14(2):114-120

22. Paolisso G, Tagliamonte MR, Galderisi M, Zito GA, Petrocelli A, Carella C, de Divitiis O, Varricchio M (1999) Plasma leptin level is associated with myocardial wall thickness in hypertensive insulinresistant men. Hypertension 34(5):1047-1052

23. Perego L, Pizzocri P, Corradi D, Maisano F, Paganelli M, Fiorina P, Barbieri M, Morabito A, Paolisso G, Folli F, Pontiroli AE (2005) Circulating leptin correlates with left ventricular mass in morbid (grade III) obesity before and after weight loss induced by bariatric surgery: a potential role for leptin in mediating human left ventricular hypertrophy. J Clin Endocrinol Metab 90(7):4087-4093

24. Vasan RS, Levy D (1996) The role of hypertension in the pathogenesis of heart failure. A clinical mechanistic overview. Arch Intern Med 156(16):1789-1796

25. Mark AL (2013) Selective leptin resistance revisited. Am J Phys Regul Integr Comp Phys 305(6):R566-R581. https://doi.org/10. 1152/ajpregu.00180.2013

26. Kain D, Simon AJ, Greenberg A, Ben Zvi D, Gilburd B, Schneiderman J (2018) Cardiac leptin overexpression in the context of acute MI and reperfusion potentiates myocardial remodelling and left ventricular dysfunction. PLoS One 13(10):e0203902. https://doi.org/10.1371/journal.pone.0203902 eCollection 2018

27. Windham BG, Griswold ME, Farasat SM, Ling SM, Carlson O, Egan JM, Ferrucci L, Najjar SS (2010) Influence of leptin, adiponectin, and resistin on the association between abdominal adiposity and arterial stiffness. Am J Hypertens 23(5):501-507. https://doi.org/10.1038/ajh.2010.8

28. Kamimura D, Suzuki T, Wang W, deShazo M, Hall JE, Winniford MD, Kullo IJ, Mosley TH, Butler KR, Hall ME (2018) Higher plasma leptin levels are associated with reduced left ventricular mass and left ventricular diastolic stiffness in black women: insights from the genetic epidemiology network of Arteriopathy (GENOA) study. Hypertens Res 41(8):629-638. https://doi.org/10.1038/ s41440-018-0062-0

29. Lieb W, Sullivan LM, Aragam J et al (2009) Relation of serum leptin with cardiac mass and left atrial dimension in individuals $>70$ years of age. Am J Cardiol 104(4):602-605. https://doi.org/ 10.1016/j.amjcard.2009.04.026

Publisher's note Springer Nature remains neutral with regard to jurisdictional claims in published maps and institutional affiliations. 